\title{
The Effects of Voltage Flow and pH Value in Alkaline electrolyser System to Performance
}

\author{
Mohammad Nazry Bin Rosley 1,2,a , Noreffendy Bin Tamaldin 1,2,b, \\ M. F. B Abdollah ${ }^{1,2, \mathrm{c}}$, and Z.M. Zulfattah ${ }^{1,2, \mathrm{~d}}$ \\ ${ }^{1}$ Centre for Advanced Research on Energy (CARe) \\ ${ }^{2}$ Faculty of Mechanical Engineering, Universiti Teknikal Malaysia Melaka \\ 76100 Durian Tunggal, Melaka, Malaysia \\ a nazryrosley@student.utem.edu.my, ${ }^{\text {b }}$ noreffendy@utem.edu.my, ${ }^{c}$ mohdfadzli@utem.edu.my, \\ dzulfattah@utem.edu.my
}

Keywords: Alternative fuel, hydrogen production, alkaline electrolyser, electrolyte, voltage flow, $\mathrm{pH}$ value.

\begin{abstract}
The aim of this paper is to investigate the effects of voltage flow (V) in the alkaline electrolyser system and the $\mathrm{pH}$ value $(\mathrm{pH})$ of the electrolyte used in the electrolyser. The output measurement of both investigated factors in in the flow rate of the hydrogen gas produced by the system per minute $(\mathrm{ml} / \mathrm{min})$. The voltage flow was altered in the system by altering the voltage supply from the workbench power supply ranging from $11 \mathrm{~V}$ to $14 \mathrm{~V}$. The $\mathrm{pH}$ value of the electrolyte solution in the electrolyser was altered by the addition of Potassium Hydroxide $(\mathrm{KOH})$ in the distilled water. The $\mathrm{pH}$ value samples of the tested solution ranging from 13.0 to $14.0 \mathrm{pH}$ value due to the limitation of the electrolyser used in this experiment. The results found that, the hydrogen gas produced per minute increases with voltage flow in the system. The flow rate of the hydrogen gas produced however only increases when the solution's $\mathrm{pH}$ value reaches at $14 \mathrm{pH}$ level and unreactive below the value.
\end{abstract}

\section{Introduction}

The energy user all over the world need to stop depending on the fossil fuels as the main energy source due to the facts that the commodity is volatile in global markets. This can be proven by the recent fossil fuels price hike which has created massive shocks throughout the world in terms of economics and politics. For that reason, researchers all over the world has gathered around to search for alternative fuels that can substitute the dependencies of the world toward the fossil fuels usage. Hydrogen shows promising characteristics as fuel since it is considered as green and eco-friendly energy resources. Hydrogen unlike any other types of fuel, will only emits water as the waste product after combustion thus making it practical to be used massively without damaging the environment. In terms of hydrogen production, hydrogen has the advantage of to be the most abundant elements in the planet [1-2]. The abundant of hydrogen making it to be a renewable fuel. Hydrogen also is efficient to be used as an alternative fuel since it is safe, clean, light, and affordable to be produced [3-6]. Hydrogen has proven to be a resources that contains higher energy that the fossil fuels. It is estimated that 1 kilogram of hydrogen possess the same energy as 1 gallons of diesel or gasoline [7]. Electrolysis is the most promising and proven technology to extract extremely pure hydrogen to be utilize as alternative fuel [6-9]. Electrolysis is basically a process that splits water to become oxygen and hydrogen gas [9-14]. There many types of electrolyser that can be used to extract hydrogen from water but the most preferable electrolyser is the alkaline electrolyser since it is simple and less demanding process [1].

In this publication, the research focused on the simple alkaline type of electrolyser. The performance of the alkaline electrolyser will be studied in referred to the voltage flows (V) and also 
the $\mathrm{pH}$ concentration used in the electrolyte. Both of the factors are monitored to determine the best conditions so that the alkaline electrolyser can perform well. The performance measurement of the electrolyser is from the hydrogen gas production per minute $(\mathrm{ml} / \mathrm{min})$. From the previous studies conducted, it is shown that the increase of voltage flow in the system will increase the hydrogen gas production by the system $[1,12]$. Other than that, others studies also shown that the $\mathrm{pH}$ value of the electrolyte used in the system can helps to accelerate the reaction of the electrolysis, thus increasing the hydrogen gas production as well $[3,15]$.

\section{Electrolysis of water}

The electrolyser splits the water molecules into its basic elements which are the hydrogen and oxygen with the help of constant flow of electric energy. The overall reaction can be shown as in Eq. 1 below [13-14]:

$$
\mathrm{H}_{2} \mathrm{O}+\text { electrical energy } \longrightarrow \mathrm{H}_{2}+1 / 2 \mathrm{O}_{2}
$$

When the electrolysis occurred, the electron from the negatively charged terminal of the cathode enters the electrolyser. The electron then will be used by the hydrogen ions from the water to break up its bond with its neighbouring oxygen. As a results, the water was split into both positively charged hydrogen ions and negatively charged ions to become oxy-hydrogen gas. The oxyhydrogen gas will then be separated by the diaphragm where the positively charged hydrogen ions will travel to the cathode to become hydrogen gas while the negatively charged hydroxide ion will travel to anode to become oxygen gas. The positively charged hydrogen ion upon arriving on the cathode, will gain electrons from the anode thus changing it into hydrogen gas. Simultaneously to ensure the electrical charge of the system balance, the hydroxide ions from the electrolyte then will travel to the positive anode to give away its electron to become oxygen gas. The electron then will travel back to the positive terminal of the power supply to complete the electrical circuit $[8,9,12]$. The hydrogen gas production at the cathode can be explain by the Eq. 2 and the oxygen gas production at the anode can be explain by the Eq. 3 .

Cathode and anode reaction during electrolysis $[2,5,6,8,9]$ :

Cathode: $2 \mathrm{H}^{+}+2 \mathrm{e}^{-} \longrightarrow \mathrm{H}^{2}$

Anode: $2 \mathrm{OH}^{-} \longrightarrow 1 / 2 \mathrm{O}_{2}+\mathrm{H}_{2} \mathrm{O}+2 \mathrm{e}^{-}$

\section{Methods}

The alkaline electrolyser design was set to be the same in both of the experiment to control unnecessary variables. There are 16 electrodes $15 \mathrm{~cm} \mathrm{x} 10 \mathrm{~cm}$ X $0.33 \mathrm{~cm}$ stacked together in the electrolyser which each one of them are made from stainless steel $316 \mathrm{LN}$. The overall system that was used in this experiment consists of a DC unregulated power supply, an alkaline electrolyser, a bubbler, and also a simple gas trap. The overall schematic diagram of the system is as show in the Fig. 1 below. 


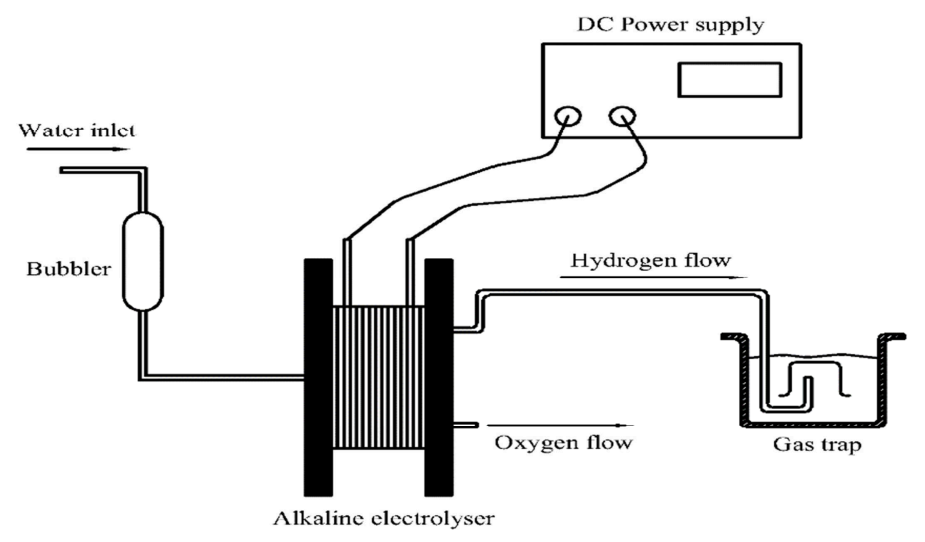

Fig. 1 Experimental set up

Effects of Voltage. The instruments and apparatus was set as shown in Fig.1. In this experiment the $\mathrm{pH}$ value of the electrolyte was set constant at $14.0 \mathrm{pH}$ value which is the maximum $\mathrm{pH}$ value that the electrolyser can withstand. The voltage flow of the electrolyser system was altered ranging from $11 \mathrm{~V}$ to $14 \mathrm{~V}$ with the increment of 0.5 per trial. The hydrogen gas produced in the gas trap was recorded in respect to the voltage flow alteration.

Effects of pH value. The instruments and apparatus was set as shown in the Fig. 1. In this experiment the voltage flow was set constant at $12 \mathrm{~V}$ to replicate the actual voltage of a normal car battery operates. The $\mathrm{pH}$ value of the electrolyte was altered by the addition of potassium Hydroxide compound in the pure water. The $\mathrm{pH}$ was set ranging from $13.0 \mathrm{pH}$ up until $14.0 \mathrm{pH}$ with the increment of $0.1 \mathrm{pH}$ level per trial. The hydrogen gas produced in the gas trap was recorded in respect to the $\mathrm{pH}$ value alterations. The experiment will stop at $14.0 \mathrm{pH}$ value due to the limitations of the electrolyser.

\section{Results \& Discussion}

From the experiment, the performance of the alkaline electrolyser was measured by the hydrogen flow rate that was produced when subjected to the various determined variables. There are two relationship that was studied which can be illustrated as Fig 2 and Figure 3.

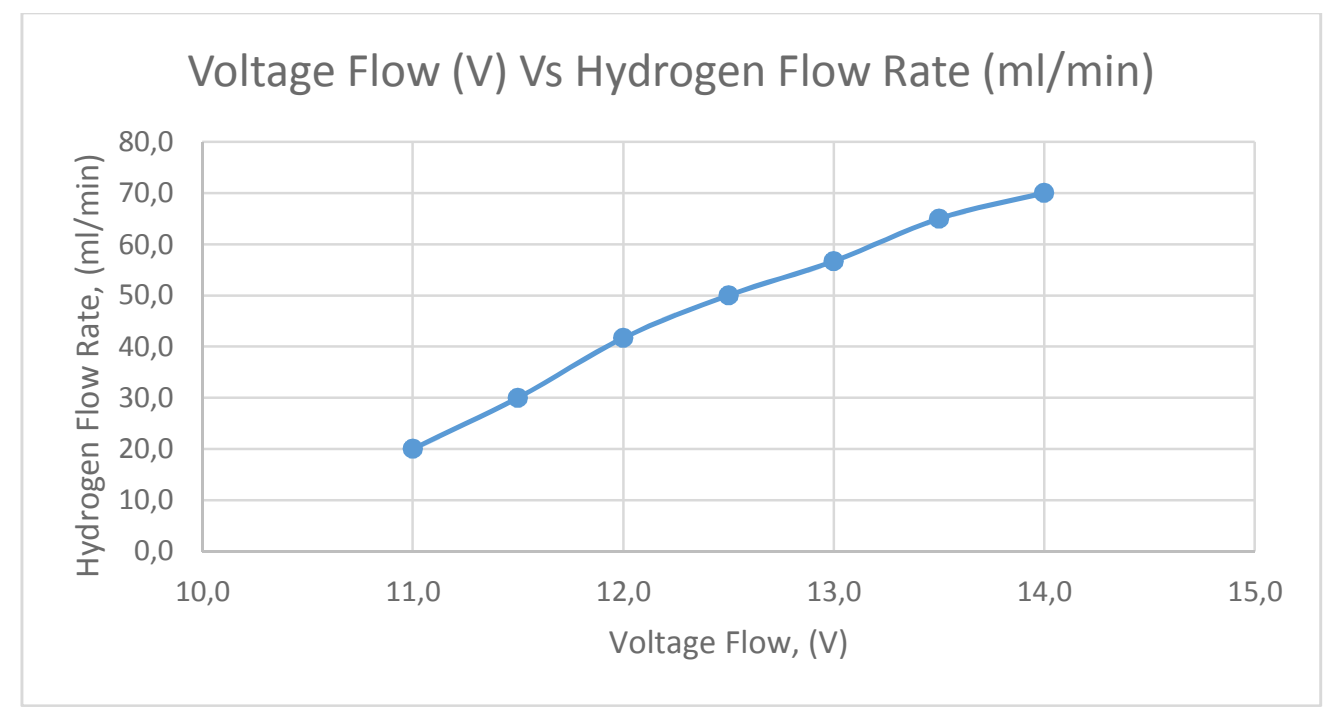

Fig. 2 Hydrogen gas produced per minute in respect to voltage flow in the electrolyser 
From the Fig. 2, the hydrogen flow rate produced from the electrolyser increases with the increment of voltage supplied to the system. This is due to the facts by increasing the voltage of the system, the current also increases as well. The Ohm's Law has stated the current, U and voltage, V relationship with the presence of resistance, $\mathrm{R}$ in the following relationship as stated in Eq. 4.

$$
\mathrm{V}=\mathrm{UR}
$$

The input current is necessarily since the current provide energy in forms of electrons for electrolysis process to occur hence more electron exchange can happen with the positively charged hydrogen ion. Vigorous supply of voltage can increase the speed of hydrogen formation from water.

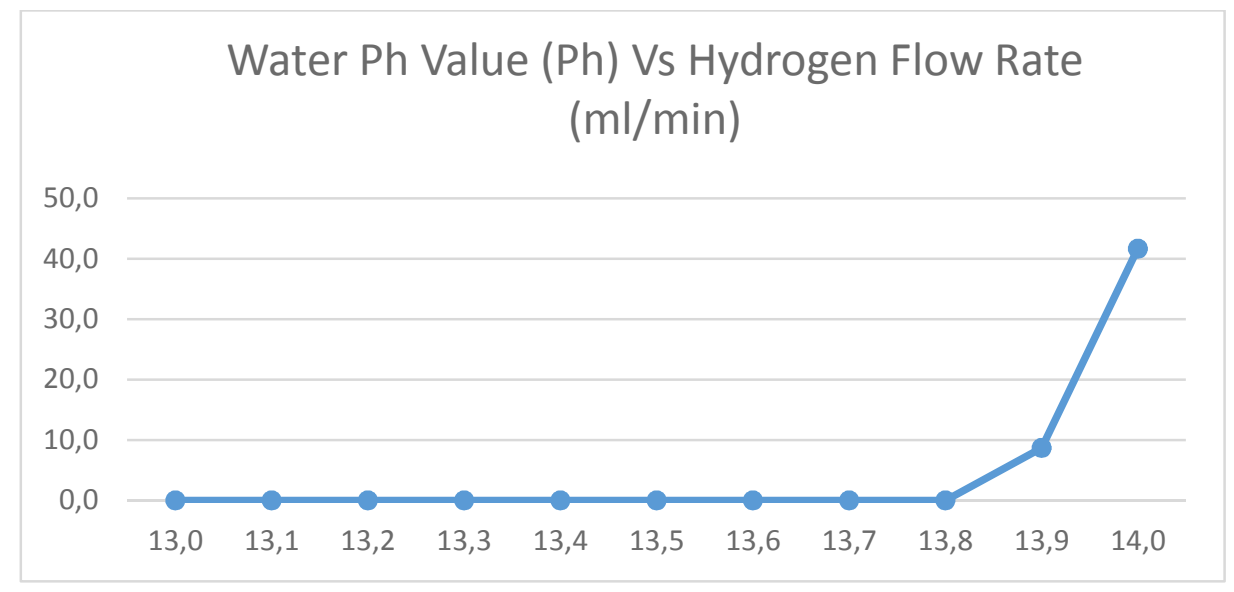

Fig. 3 Hydrogen gas produced per minute in respect to water $\mathrm{pH}$ value

From the Fig. 3, the hydrogen gas flow rate produced from the electrolyser only started to increases at certain $\mathrm{pH}$ value and continue to shows increment as the $\mathrm{pH}$ value increases. This is due to the facts that water itself is a bad electrical conductor. The electrolysis of water can occur due to the mobile ions that moves freely in the electrolyte. The addition of potassium hydroxide $(\mathrm{KOH})$ in the electrolyte is necessarily to increase the conductivity of the electrolyte by providing higher concentration of mobile hydroxide ions to the electrolyte. However the $\mathrm{pH}$ value eventually can causes degradation to the electrodes in the electrolyser if exceeds the maximum suggested $\mathrm{pH}$ of the electrolyser.

\section{Conclusion}

As for conclusion, the factors that can effects the performance of an alkaline electrolyser are voltage flow and also $\mathrm{pH}$ value. The performance of the electrolyser measured by hydrogen gas produced shows increment in production if higher voltage was subjected to the system. Other than that, the addition of potassium hydroxide inside the electrolyte can catalyse the electrolysis process. The following findings has verify the previous researchers' findings.

\section{References}

[1] Dharmaraj C.H., AdishKumar S., Economical hydrogen production by electrolysis using nano pulsed DC, Int. J. of Energy \& Environment, 3 (2012) 129-136

[2] Thorsteinn I. Sigfusson, Pathways to hydrogen as an energy carrier, Phil. Trans. R. Soc. A, 365 (2007) 1025-1042

[3] A-F.M. Mahrous, I.M. Sakr, A. Balabel, K. Ibrahim, Experimental Investigation of the Operating Parameters Affecting Hydrogen Production Process through Alkaline water Electrolysis, Int. J. of Thermal \& Environmental Engineering, 2 (2011) 113-116 
[4] E.L. Santhi priya, C. Mahender, Naga Mahesh, V. Himabindu, Y. Anjaneyulu, Production of hydrogen using composite membrane in PEM water electrolysis, Int. J. of Energy \& Environment, 3 (2012) 731-738

[5] N. Chennouf, N. settou, B. Negrou, K. Bouziane, B. Dokkar, Experimental study of Solar Hydrogen Production by Water Electrolysis in the south of Algeria, Energy Procedia 18 (2012) $1280-1288$

[6] Kai Zeng, Dongke Zhang, Recent progress in alkaline water electrolysis for hydrogen production and application, Progress in Energy and Combustion Science 36 (2010) 307-326

[7] Michael E. Webber, The water intensity of the transitional hydrogen economy, Environ. Res. Lett. 2 (2007) 1-7

[8] Yadav Millind S., Sawant S.M., Anavkar Jayesh A., Chavan Hemant V., Investigation on generation methods for oxy-hydrogen gas, its blending with conventional fuels and effect on the performance of internal combustion engine, J. of Mechanical Engineering Research, 3 (2011) 325332

[9] Daniel Santoso, Franciscus Dalu Setiaji, Deddy Susilo, Demonstration of Renewable Electrical Energy Generation based on Solar-Hydrogen Fuel Cell Technology, 2011 International Conference on Instrument, Communication, Information Technology and Biomedical Engineering, (2011), available at: http://ieeexplore.ieee.org/xpls/abs_all.jsp?arnumber $=6108655$, access on: $8^{\text {th }}$ January 2014

[10] Andress Zuttel, arndt Rehmof, Andreas Borgschulte, Hydrogen: the future energy carrier, Phil. Soc. A, 368 (2010) 3329-3342

[11] A. Djafour, M. Matoug, H. Bouras, B. Bouchekima, M.S. Aida, B. Azoui, Photovoltaicassisted alkaline water electrolysis: Basic principles, Int. J. of Hydrogen Energy 36 (2011) 41174134

[12] Daniel Symes, Bushra Al-Duri, Waldemar Bujalski, aman Dhir, Cost-effective design of the alkaline electrolyser for enhanced electrochemical performance and reduced electrode degradation, Int. J. of Low-Carbon Technologies, (2013) 1-8

[13] Kaveh Mazloomi, Nasri b. Sulaiman, Hossein Moayedi, Electrical Efficiency of Electrolytic Hydrogen Production, Int. J. Electrochem. Sci., 7 (2012) 3314-3326

[14] S.K. Mazloomi, Nasri Sulaiman, Influencing factors of water electrolysis electrical efficiency, Renewable and Sustainable Energy Reviews, 16 (2012) 4257-4263

[15] Salah Abdallah, Essam Yousef, Mohammad Katab, Issameddin Abdullah, The Effect of PH on the Hydrogen and Oxygen Production Using Photovoltaic Power Generator, Int. J. of Suistainable Water and Environmental Systems, 5(2013) 7-12 